\title{
Alternative approaches for thinking about and modeling consumer decisions in relationships
}

\author{
Richard P. Bagozzi * \\ Ross School, University of Michigan, Ann Arbor, MI 48109-1234, USA \\ Available online 5 May 2012
}

\begin{abstract}
Simpson, Griskevicius, and Rothman identify an understudied area in consumer research (namely, decision making in social relationships), propose an important starting point for enquiry (a dyadic framework), and suggest many fruitful moderators for study that can be incorporated in their framework. After pointing out some boundary conditions and opportunities for future research concerning their suggestions, I consider a recent approach in psychology that applies to a relatively circumscribed domain of social relationships (i.e., the social relations model) and then briefly review an emerging approach (plural subject theory applied to goal-directed behavior) that goes beyond the social relations model and better fits certain psychological and social psychological phenomena in consumer behavior.
\end{abstract}

(C) 2012 Society for Consumer Psychology. Published by Elsevier Inc. All rights reserved.

Keywords: Plural subject theory; Social relations model; Key informant model; Social relationships

\section{Introduction}

Consumer decision making in relationships is ubiquitous, important to study, and in need of new conceptual and methodological ideas. Simpson, Griskevicius, and Rothman (in press) provide a thoughtful treatment that makes two contributions. First, SGR propose a dyadic approach to decision-making, wherein a particular statistical methodology is proposed to analyze this dependence of choice/behavior on preferences of two persons in a relationship, and preferences, in turn, are posited to be functions of the attitudes and beliefs of the separate persons. Second, they suggest a number of theories of relationships that can be introduced as moderators of the effects of attitudes, beliefs, and preferences on decision making.

\section{SGR's dyadic approach to decision-making}

SGR contrast individual person models, where one person's preference influences his/her choice/behavior (call this the

\footnotetext{
The author would like to thank Dr. Rachel Oakley Hsiung and Dr. Julie A. Ruth for ideas addressed in here.

* Fax: +1 7349368715

E-mail address: bagozzi@umich.edu.
}

intrapersonal model, IM), to dyadic models, where the preferences, attitudes, and beliefs of each of two people in a relationship influence the choice/behavior of the people as a unit (call this the dyadic model, DM). The first issue I wish to raise is that a theory is lacking under the DM for explaining how preferences of the individual people in the relationship determine a shared outcome (i.e., the joint decision or choice; e.g., a restaurant two partners choose for dinner). The theories discussed at the end of their article do not address this gap but rather constitute moderators of the relationships in the DM that are in need of theoretical specification. Under the IM, a number of theories might be brought to bear to explain how the preferences of an individual person influence one's individual choice (e.g., attitude theory, motivation theory). However, no theory was considered by SGR for explaining how individual preferences determine mutual decision outcomes. Rather, the paths in their Figs. 2 and 3 linking preferences to choice/ behavior reflect correlations or empirical predictions but are not grounded in theory. What are needed are theories of interpersonal processes transforming or reconciling the psychological reactions or responses of two individual persons into a mutually agreed upon social outcome. This is not merely a matter of prediction but rather requires a theory explaining the predictions and bridging individual and social (dyadic) 
behavior. I regard this as a key challenge to SGR's framework but an opportunity for original theorizing needed to bring the promise of the DM to fruition. Later in this commentary, plural subject theory is considered as one approach grounded in theory, but other approaches could be developed too. SGR are to be commended for setting the stage for a theory(ies) addressing the individual to group level (or the individual to shared level) gap.

As a digression, I want to mention another conceptual and empirical challenge. In all the models considered by SGR (see their Figs. 1-3), preference for one option or another is determined by a simple additive sum of attitudes and beliefs for the two options. This specification leaves open how attitudes and beliefs are incorporate, absorbed, or reconciled to produce one's preferences. A number of alternative theories have been proposed for explaining the preference for an option as a function of attributes, beliefs, evaluations of options and attitudes towards options for IM models (for one example, see Dabholkar, 1994). This makes for considerable complexity, especially when incorporated into models for persons in dyads, which is not apparent in SGR's models and figures and is not discussed in their article. Because their DM model implies that dyadic preferences are functions of one's own attitudes and beliefs with regard to options, as well as the attitudes and beliefs of another person, the number and complexity of theoretical formulations needed to specify and test SGR's models are more challenging than meets the eye. This issue will be exacerbated to the extent that multiple attributes and options in choices occur. Moreover, the many theoretical possibilities pose special statistical challenges that should be considered in future work.

A second issue is the nature and adequacy of the dyadic framework proposed by SGR. SGR mention problems with assumptions of statistical independence that arise when responses are incorporated from two people in a relationship, and they also discuss the need to take into account changes in partner effects over time, which they do, in part, by specifying "double-arrowhead curved paths" in their Fig. 2 for example. However, what is missing in their models and presentation is recognition of special conceptual and measurement issues.

For example, models and assumptions may differ whether one is studying so-called distinguishable dyads where special roles or constraints occur (e.g., dyads with husbands and wives) or indistinguishable dyads (e.g., ones with two friends) where the parties are in some sense equal or comparable roles. Under some conditions, correlations between certain pairs of error terms for multiple measures of variables will need to be specified as free parameters. For instance, correlated error terms for measures of attitudes, beliefs, and preferences need to be estimated in the model shown in Fig. 2 in SGR's article. This poses specification and estimation challenges, depending on the structure of the model and number of measures. Some of what are termed actor-partner interdependence models (APIMs) by Kenny, Kashy, and Cook (2006) involve pooled-regression models, multilevel analysis, or analyses done with the dyad as a unit of analysis. However, these variants may require different theoretical frameworks and assumptions and different statistical premises than that implied by the models that SGR sketch. The specifications and assumptions underpinning the APIM make for a narrower and more refined approach in one sense than that proposed by SGR, and important distinctions and limitations need to be considered that are beyond the scope of this commentary.

\section{The social relations model}

Kenny et al. (2006) discuss a broader model than considered by SGR, the so-called social relations model (SRM). The SRM permits one to not only model actor and partner effects, as under the APIM, but also group level, relationship, generalized reciprocity, individual reciprocity, and dyadic reciprocity effects. However, at least 3 persons in a relationship (e.g., father, mother, child in a family) are needed to estimate many of these effects, and 4 or more persons are needed to estimate all of them. The actor and partner effects under the models considered by SGR are confounded with aspects of the other effects listed above for the SRM.

A frequently used approach under the SRM is called a round-robin design (e.g., Kenny et al., 2006). In a round-robin design each person in a group of three or more persons rates the other members in the group on the same variable. For example, imagine a family consisting of a child (C), mother (M), and father (F) and that we wish to measure the degree of felt frustration during a time when the family is making a consumption decision such as what restaurant to choose for dinner (see for example, Hsiung, Ruth, and Bagozzi, in press). Under a round-robin design, $C$ estimates M's frustration with $F$ and F's frustration with $\mathrm{M} ; \mathrm{M}$ estimates $\mathrm{C}$ 's frustration with $\mathrm{F}$ and F's frustration with $\mathrm{C}$; and $\mathrm{F}$ estimates $\mathrm{C}$ 's frustration with $\mathrm{M}$ and M's frustration with $\mathrm{C}$. Given these six measurements from the three family members, Bagozzi and Hsiung (1994, Fig. 1) show how structural equation models can be used in a variance-decomposition approach to ascertain $\mathrm{C}, \mathrm{M}$, and $\mathrm{F}$ actor effects; C, M, and F partner effects; and individual reciprocity and dyadic reciprocity effects. With two measures per variable (e.g., two items measuring frustration in each of the six round-robin cases noted above), it is possible to estimate relationship effects in addition to actor, partner, individual reciprocity, and dyadic reciprocity effects (see Bagozzi and Hsiung, 1994, Fig. 2). With four member groups (e.g., M. F, son, daughter) and one item for each of the six round-robin cases, one can estimate actor, partner, individual reciprocity, actor-actor synchrony, partner-partner synchrony, and group level effects (Bagozzi and Hsiung, 1994, Fig. 3); with four group members and two items for each of the six round-robin cases, one can further ascertain relationship effects and dyadic reciprocity effects, in addition to the effects under the four member, one item case (Bagozzi and Hsiung, 1994, Fig. 4).

Hsiung and Bagozzi (2003) provide an illustration of the SRM for $\mathrm{C}, \mathrm{M}$, and $\mathrm{F}$ family decision making in the case of buying a new car; Bagozzi, Ascione, and Mannenbach (2005) give an example for four-member group decision making for the case in which drug formularies are considered for purchase for hospitals by members of pharmacy and therapeutics 
committees. Some recent examples of new developments in or applications of SRMs can be seen in Bonito and Kenny (2010) who show how reliability of SRM components can be estimated, Rasbash, Jenkins, O'Connor, Tackett, and Reiss (2011) who investigate expressions of negativity and positivity in families, and Ackerman, Kashy, and Donellan (2011) who examine interpersonal styles in families marked by attentiveness, warmth, cooperation, and clear communication.

As with any approach, the SRM has limitations. One concerns the complexity of models, which require the use of SEMs. A second is that at least 3, preferably 4 or more, members are required per group for purposes of estimation of the distinct actor, partner, and relationship effects. Finally, the SRM model focuses on very specific sources of variance in variables that correspond to different and perhaps seemingly strange aspects of social relationships. The SRM does not lend itself to the investigation of many causal relationships of the sort normally studied by social psychologists and consumer researchers, although the phenomena it does examine are interesting and relevant for consumer behavior. The approach we turn to now overcome this latter limitation.

\section{Plural subject theory and goal-directed behavior}

Many actions are done jointly such that two or more people mutually form a decision to act, so as to achieve a common goal and to act together to strive for it. Emotional, motivational, and cognitive antecedents to the shared decision are also frequently formed or held jointly as well.

There are a number of approaches that may be applied to such decision making involving relationships between people. One is to aggregate responses of individuals in a group and perform analyses at the group level. For example, responses of family members concerning their judgments, preferences, and purchases might be averaged, and these variables could be related in hypotheses according to a theory and tested at the level of the family. Researchers in small group and organization behavior traditions sometimes study team behavior this way.

An alternative approach is based, not on aggregation, but rather on using information provided by members in a group or people relating to each other to measure shared properties of the group or organized social relationships. The variables so measured then enter into hypotheses and can be tested by new statistical models. Building on plural subject theory drawn from philosophy (e.g., Gilbert, 1989; Tuomela, 2007), I have developed a model of intentional social action that explains joint behavior by individuals in a social relationship (Bagozzi, 2000, 2005). This model accounts for joint action and subsequent collective goal attainment by specifying interrelationships according to the following sequences of effects: collective goal desire $\rightarrow$ collective goal formation (goal intention) $\rightarrow$ shared desire to act to achieve goal $\rightarrow$ mutual weintentions to act to achieve goal $\rightarrow$ joint planning $\rightarrow$ joint trying to act $\rightarrow$ joint goal attainment/failure, along with shared regulation of the desire to intention relationships based on such processes as social identity, self-conscious and moral emotions, and second-order shared desires (see Bagozzi, 2005, Fig. 1).

The nature of data collection under such an approach can be seen in the example of the three person family unit shown in Table 1. Here $\mathrm{C}, \mathrm{M}$, and $\mathrm{F}$ each provide information on each person in the family unit for each variable entering the model of intentional social action (see Algesheimer, Bagozzi, and Dholakia, under review; Bagozzi, 2005, pp. 106-110). For example, consider the variable, "we-intentions" of $\mathrm{C}, \mathrm{M}$, and $\mathrm{F}$ to choose a restaurant to attend for dinner. A we-intention is the shared volition of $\mathrm{C}, \mathrm{M}$, and $\mathrm{F}$ to act together to achieve a goal (a joint behavioral intention) or to attain an end (a mutual goal intention). One measure that the $\mathrm{C}$ might provide is his/her judgment of the strength of the family unit's we-intention to attend a particular restaurant as perceived by $\mathrm{M}$ of $\mathrm{F}$. This is shown as $\mathrm{C}(\mathrm{C}(\mathrm{M}))$ in Table 1 and is a kind of dyadic judgment that $\mathrm{C}$ provides of M's belief in F's perceived we-intention. Table 1 shows 27 measures of we-intentions provided by members of the family unit: 9 by $\mathrm{C}, 9$ by $\mathrm{M}$, and 9 by F. There are 3 individual judgments $(\mathrm{C}(\mathrm{C}(\mathrm{C})), \mathrm{M}(\mathrm{M}(\mathrm{M}))$, and $\mathrm{F}(\mathrm{F}(\mathrm{F}))), 6$ dyadic judgments $(\mathrm{C}(\mathrm{C}(\mathrm{M})), \mathrm{C}(\mathrm{C}(\mathrm{F})), \mathrm{M}(\mathrm{M}(\mathrm{C})), \mathrm{M}(\mathrm{M}(\mathrm{F}))$, $\mathrm{F}(\mathrm{F}(\mathrm{C}))$, and $\mathrm{F}(\mathrm{F}(\mathrm{M})))$, and 18 second-order judgments about how each person thinks that each family unit-member evaluates all others on we-intentions $(\mathrm{C}(\mathrm{M}(\mathrm{C})), \mathrm{C}(\mathrm{M}(\mathrm{M})), \mathrm{C}(\mathrm{M}(\mathrm{F}))$, $\mathrm{C}(\mathrm{F}(\mathrm{C})), \mathrm{C}(\mathrm{F}(\mathrm{M})), \mathrm{C}(\mathrm{F}(\mathrm{F})), \mathrm{M}(\mathrm{C}(\mathrm{C})), \mathrm{MC}(\mathrm{M})), \mathrm{M}(\mathrm{C}(\mathrm{F}))$, $\mathrm{M}(\mathrm{F}(\mathrm{C})), \quad \mathrm{M}(\mathrm{F}(\mathrm{M})), \quad \mathrm{M}(\mathrm{F}(\mathrm{F})), \mathrm{F}(\mathrm{C}(\mathrm{C})), \mathrm{F}(\mathrm{C}(\mathrm{M})), \quad \mathrm{F}(\mathrm{C}(\mathrm{F}))$, $\mathrm{F}(\mathrm{M}(\mathrm{C})), \mathrm{F}(\mathrm{M}(\mathrm{M})), \mathrm{F}(\mathrm{M}(\mathrm{F})))$. The 6 entries in Table 1 enclosed by rectangles are analogous to the measures taken in a round robin design. Thus the SRM is a special case of our approach.

Another special case of interest is designated by an asterisk in Table 1. Here in addition to $\mathrm{C}, \mathrm{M}$, and $\mathrm{F}$ providing the dyadic judgments analogous to the SRM design, they provide their individual self-assessments of own shared we-intentions. This is, in effect, the key informant model proposed by Seidler (1974) in sociology as a scheme for operationalizing group properties in collectivities. Fig. 1 illustrates an adaptation of the key informant approach applied to a simple model hypothesizing that family unit we-intentions are a function of the degree of experienced attachment in the family. I have employed familiar

Table 1

Sources of measures in three-person relationship groups.

\begin{tabular}{|c|c|c|c|c|}
\hline Actor & C & M & $\mathrm{F}$ & $\begin{array}{l}\text { Person judging } \\
\text { relationship }\end{array}$ \\
\hline C & $\mathrm{C}\left(\mathrm{C}(\mathrm{C})^{*}\right.$ & $\mathrm{C}(\mathrm{C}(\mathrm{M}))^{*}$ & $\mathrm{C}(\mathrm{C}(\mathrm{F}))^{*}$ & \multirow{3}{*}{ C } \\
\hline M & $\mathrm{C}(\mathrm{M}(\mathrm{C}))$ & $\mathrm{C}(\mathrm{M}(\mathrm{M}))$ & $\mathrm{C}(\mathrm{M}(\mathrm{F}))$ & \\
\hline $\mathrm{F}$ & $\mathrm{C}(\mathrm{F}(\mathrm{C}))$ & $\mathrm{C}(\mathrm{F}(\mathrm{M}))$ & $\mathrm{C}(\mathrm{F}(\mathrm{F}))$ & \\
\hline$C$ & $\mathrm{M}(\mathrm{C}(\mathrm{C}))$ & $\mathrm{M}(\mathrm{C}(\mathrm{M}))$ & $\mathrm{M}(\mathrm{C}(\mathrm{F}))$ & \multirow{3}{*}{ M } \\
\hline M & $\mathrm{M}(\mathrm{M}(\mathrm{C}))^{*}$ & $\mathrm{M}(\mathrm{M}(\mathrm{M}))^{*}$ & $\mathrm{M}(\mathrm{M}(\mathrm{F}))^{*}$ & \\
\hline $\mathrm{F}$ & $\mathrm{M}(\mathrm{F}(\mathrm{C}))$ & $\mathrm{M}(\mathrm{F}(\mathrm{M}))$ & $\mathrm{M}(\mathrm{F}(\mathrm{F}))$ & \\
\hline C & $\mathrm{F}(\mathrm{C}(\mathrm{C}))$ & $\mathrm{F}(\mathrm{C}(\mathrm{M}))$ & $\mathrm{F}(\mathrm{C}(\mathrm{F}))$ & \multirow{3}{*}{$\mathrm{F}$} \\
\hline M & $\mathrm{F}(\mathrm{M}(\mathrm{C}))$ & $\mathrm{F}(\mathrm{M}(\mathrm{M}))$ & $\mathrm{F}(\mathrm{M}(\mathrm{F}))$ & \\
\hline $\mathrm{F}$ & $\mathrm{F}(\mathrm{F}(\mathrm{C}))^{*}$ & $\mathrm{~F}(\mathrm{~F}(\mathrm{M}))^{*}$ & $\mathrm{~F}(\mathrm{~F}(\mathrm{~F}))^{*}$ & \\
\hline
\end{tabular}

Note: $\mathrm{C}$-child, $\mathrm{M}=$ mother, $\mathrm{F}=$ father; entries encircled by rectangles are measures analogous to those found in the social relations model round robin design; entries marked with asterisk are the key informant model. 


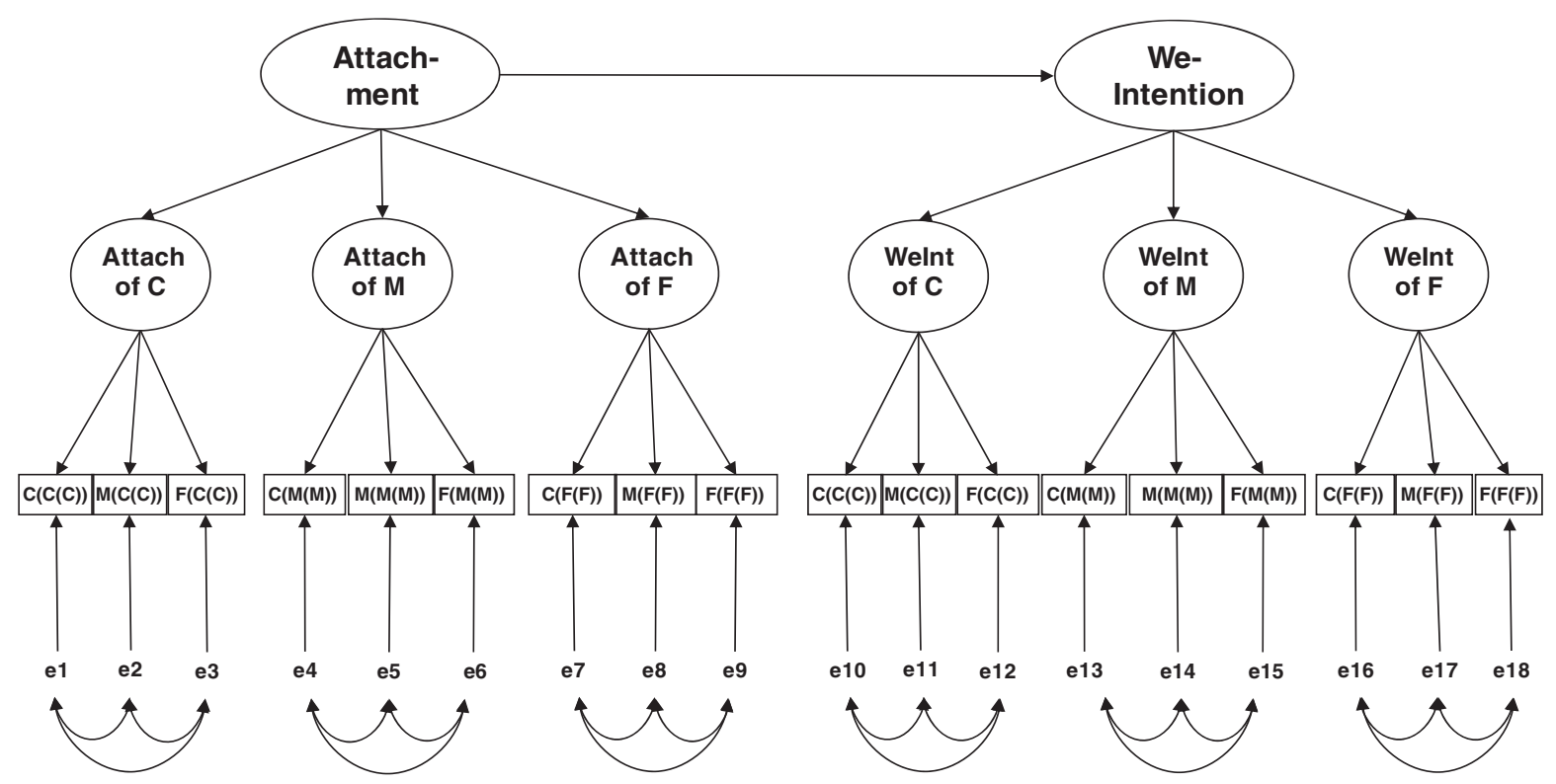

Fig. 1. Causal model of effect attachment on We-intention based on the key informant correlated trait, correlated uniqueness model. Note: $\mathrm{C}$, M, and F refer to child, mother, and father, respectively; e's refer to residuals; ellipses are latent variables; straight paths are either causal hypotheses or measurement relationships; curved lines with arrow heads are correlated residuals; parameters omitted for simplicity.

conventions found in the literature that use structural equation models, but have left-out parameter notations for simplicity (see Algesheimer et al., under review). A number of more complex models that utilize all 27 pieces of information for each variable in a model can be formulated but will not be considered here for brevity (see Algesheimer et al., under review; Bagozzi, 2005). Algesheimer et al. (under review) present an illustration of plural subject theory applied to decision making by members of three-person teams of consumers of on-line gaming activities and using structural equation models.

The structural equation model operationalization of plural subject theory has advantages over both the dyadic framework of SGR and the SRM. Statistical limitations of the former are overcome, and more information is provided in tests of hypotheses. With regard to the latter, hypotheses can be tested that better fit the type of theories drawn upon by social psychologists than the narrower type found under the SRM. In addition, the plural subject theory specification, estimation of parameters, and tests of hypotheses provide control for method bias and information on trait and method bias, which the dyadic framework and SRM do not.

\section{The nature of social relationships}

Arguably the most significant contribution by SGR is their consideration of multiple perspectives on romantic relationships. As noted above, the value of their presentation in this regard is to identify important social processes that might function as moderators of the linear relationships shown in their Figs. 2 and 3. These need not be restricted to romantic relationships but could be applied to other types of relationships in consumer behavior as well. There are of course other social processes that might be considered beyond attachment orientations, relationship dependence, power, relationship norms, evolutionary concepts, and communal and exchange processes. For example, social identity, independent versus interdependent based selves, and the role of self-conscious emotions and moral emotions in social life could be studied.

Perhaps the most promising processes of relevance to social relationships are those occurring through emotional reactions and emotional sharing and coping between or amongst consumers. Related to this is the role of empathy, which can be studied by use of fMRI and other social neuroscience methods, as well as experimentally and with questionnaires in surveys. Further, by conducting research with multiple biomarkers (e.g., fMRI, DNA, hormones) and combining this with cross-level investigations that include the study of information processing, emotions, and personality, it may be possible to get better insights into the balance between nature and nurture in consumer behavior.

\section{Conclusion}

The study of consumer decision making in relationships is not easy to do but represents an under-researched area and promises to provide needed insights in consumer behavior. By proposing a new framework for looking at decision making in relationships and suggesting a number of social processes that might moderate effects in their framework, SGR clearly have added value to our understanding in the area and point to a number of future directions for enquiry. I tried to suggest some fruitful directions in this regard too. 


\section{References}

Ackerman, R. A., Kashy, D. A., \& Donellan, M. B. (2011). Positiveengagement behaviors in observed family interactions: A social relations perspective. Journal of Family Psychology, 25(50), 719-730.

Algesheimer, R., Bagozzi, R. P., \& Dholakia, U. M. (under review). Key informant models for measuring croup-level variables in small groups, working paper.

Bagozzi, R. P. (2000). On the concept of intentional social action in consumer behavior. Journal of Consumer Research, 27, 388-396.

Bagozzi, R. P. (2005). Socializing marketing. Marketing-Journal of Research and Management, 1, 101-111.

Bagozzi, R. P., Ascione, F. J., \& Mannenbach, M. A. (2005). Inter-role relationships in hospital-based pharmacy and therapeutics committee decision making. Journal of Health Psychology, 10, 45-64.

Bagozzi, R. P., \& Hsiung, R. O. (1994). Interactions in small groups: The social relations Model. In J. N. Sheth, \& A. Parvatiyar (Eds.), Relationship Marketing: Theory, Method and Applications (pp. 1-10). Atlanta, GA: Center for Relationship Marketing, Robert C. Goizueta Business School, Emory University.

Bonito, J. A., \& Kenny, D. A. (2010). The measurement of reliability of social relations components from round-robin designs. Journal of the International Association for Relationship Research, 17, 235-251.
Dabholkar, P. A. (1994). Incorporating choice into an attitudinal framework: Analyzing models of mental comparison processes. Journal of Consumer Research, 21, 100-118.

Gilbert, M. (1989). On social facts. London: Routledge.

Hsiung, R. O., \& Bagozzi, R. P. (2003). Validating the relationship qualities of influence and persuasion with the family relations model. Human Communication Research, 29, 81-110.

Hsiung, R. O., Ruth, J. A., \& Bagozzi, R. P. (in press). Social foundations of emotions in family consumption decision making. Social Influence.

Kenny, D. A., Kashy, D. A., \& Cook, W. L. (2006). Dyadic data analysis. New York: Guilford Press.

Rasbash, J., Jenkins, J., O’Connor, T. G., Tackett, J., \& Reiss, D. (2011). A social relations model of observed family negativity and positivity using a genetically informative sample. Journal of Personality and Social Psychology, 100(3), 474-491.

Seidler, J. (1974). On using key informants: A technique for collecting quantitative data and controlling for measurement error in organization analysis. American Sociological Review, 39, 816-831.

Simpson, J. A., Griskevicius, V., \& Rothman, A. (in press). Consumer Decisions in Relationships. Journal of Consumer Psychology.

Tuomela, R. (2007). The philosophy of sociality: The shared point of view. Oxford, UK: Oxford University Press. 